\title{
CONVEX SUM OF UNIVALENT FUNCTIONS
}

\section{PRAN NATH CHICHRA and RAM SINGH}

(Received 22 April 1970; revised 9 September 1970)

Communicated by E. Strzelecki

\section{Introduction}

Let $f(z)=z+\cdots$ be regular in the unit disc $|z|<1$ (hereafter called $E$ ). In a recent paper Trimble [7] has proved that if $f(z)$ be convex in $E$, then $F(z)=(1-\lambda) z+\lambda f(z)$ is starlike with respect to the origin in $E$ for $(2 / 3) \leqq \lambda \leqq 1$. The purpose of this note is to show that if certain additional restrictions be imposed on $f(z)$, then $F(z)$ becomes starlike for all $\lambda, 0 \leqq \lambda \leqq 1$. Also we consider some related problems.

\section{2}

THEOREM 1. If $f(z)$ be convex in $E$, then

$$
F(z)=\frac{2 \lambda}{z} \int_{0}^{z} f(z) d z+(1-\lambda) z
$$

is starlike w.r.t. the origin in $E$ for all $\lambda, 0 \leqq \lambda \leqq 1$.

Proof. Let

$$
g(z)=\frac{2}{z} \int_{0}^{z} f(z) d z .
$$

Then it is known that $g(z)$ is also convex in $E$ [2]. From (1), we have

$$
\frac{z F^{\prime}(z)}{F(z)}=\frac{\mu z+2 f(z)-g(z)}{\mu z+g(z)}
$$

where $\mu=(1-\lambda) / \lambda$. Now

and

$$
\frac{z F^{\prime}(z)}{F(z)}-1=\frac{2(f(z)-g(z))}{\mu z+g(z)}
$$

$$
\frac{z F^{\prime}(z)}{F(z)}+1=\frac{2(\mu z+f(z))}{\mu z+g(z)} .
$$


For $F(z)$ to be starlike w.r.t. the origin in $E$, it is both necessary and sufficient that $\operatorname{Re}\left(z F^{\prime}(z) / F(z)\right)>0$ for all $z$ in $E$. This condition is satisfied if

$$
\left|\frac{z F^{\prime}(z)}{F(z)}-1\right|<\left|\frac{z F^{\prime}(z)}{F(z)}+1\right|,
$$

for all $z$ in $E$. The above condition in our case is equivalent to

$$
\left|1-\frac{g(z)}{f(z)}\right|<\left|1+\frac{\mu z}{f(z)}\right| \text {. }
$$

From (2), we have

$$
\frac{f(z)}{g(z)}=\frac{1}{2}\left[\frac{z g^{\prime}(z)}{g(z)}+1\right] .
$$

Since $g(z)$ is convex (and in particular, starlike w.r.t. the origin in $E$ ), therefore $\operatorname{Re}\left(z g^{\prime}(z) / g(z)\right)>0$. Consequently

$$
\operatorname{Re}(f(z) / g(z))>\frac{1}{2},
$$

for all $z$ in $E$. This is equivalent to

$$
\left|\frac{g(z)}{f(z)}-1\right|<1
$$

for all $z$ in $E$. Also $f(z)$ being convex, $\operatorname{Re}(f(z) / z)>\frac{1}{2}>0$ [6] for all $z$ in $E$. Therefore

$$
\left|1+\frac{\mu z}{f(z)}\right| \geqq \operatorname{Re}\left(1+\frac{\mu z}{f(z)}\right) \geqq 1,
$$

for $z$ in $E$. From (5) and (6), it follows that (4) is satisfied for all $z$ in $E$.

REMARK. To prove the above theorem, we have in fact made use of much weaker assumptions, viz., (i) $f(z)$ is starlike, and (ii) $\operatorname{Re}(f(z) / z)>0$. For if $f(z)$ be starlike in $E$ then $g(z)$ is also starlike in $E$ [2].

The following simple theorem leads to interesting results.

THEOREM 2. If $f(z)$ be starlike and $\operatorname{Re} f^{\prime}(z)>0$ for $z$ in $E$, then

$$
F(z)=(1-\lambda) z+\lambda f(z)
$$

is starlike and $\operatorname{Re} F^{\prime}(z)>0$ for $z$ in $E$.

Proof. From (7), we have

$$
\frac{z F^{\prime}(z)}{F(z)}=\frac{\mu z+z f^{\prime}(z)}{\mu z+f(z)}
$$




$$
=\frac{\mu}{\mu+\frac{f(z)}{z}}+\frac{1}{\frac{\mu}{f^{\prime}(z)}+\frac{f(z)}{z f^{\prime}(z)}},
$$

where $\mu=(1-\lambda) / \lambda$. Since $\operatorname{Re} f^{\prime}(z)>0$ for $z$ in $E$, therefore $\operatorname{Re}(f(z) / z)>0$ for $z$ in $E$ [5]. Making use of this and the given facts, it is now easy to see that $\operatorname{Re}\left(z F^{\prime}(z) / F(z)\right)>0$ for all $z$ in $E$.

Corollary 1. If $f(z)$ be convex in $E$, then

$$
F(z)=(1-\lambda) z+\lambda \int_{0}^{z} \frac{f(z)}{z} d z
$$

is starlike in $E$ for all $\lambda, 0 \leqq \lambda \leqq 1$. Also $F(z)$ is univalent in $E$ for all $\lambda, 0 \leqq \lambda \leqq 2$.

The corollary follows from Theorem (2) on writing

$$
g(z)=\int_{0}^{z} \frac{f(z)}{z} d z
$$

and noting that $\operatorname{Re} g^{\prime}(z)=\operatorname{Re}(f(z) / z)>\frac{1}{2}>0$ [6] for $z$ in $E$. The last statement in the above corollary follows from a result of Noshiro [3], on noting that $\operatorname{Re} F^{\prime}(z)>0$ in $E$ for all $\lambda, 0 \leqq \lambda \leqq 2$.

From Trimble's result [7] it follows that $\{\lambda / n\}$ is a convexity preserving sequence (For the definition of c.p. (convexity preserving) sequence, see, for example [1]) for $\lambda \geqq 2 / 3$, whereas from corollary 1 , it follows that $\left\{\lambda / n^{2}\right\}$ is a c.p. sequence for all $\lambda, 0 \leqq \lambda \leqq 1$. Combining this result with the well-known fact that $\{l / n\}$ is c.p. sequence, it follws that $\left\{\lambda / n^{p}\right\}$ is c.p. sequence for all $\lambda, 0 \leqq \lambda \leqq 1$, and for all $p \geqq 2$.

COROLlary 2. If $f(z)$ be an odd convex function in $E$, then

$$
F(z)=(1-\lambda) z+\lambda f(z)
$$

is starlike in Efor all $\lambda, 0 \leqq \lambda \leqq 1$. Also $F(z)$ is univalent in Efor all $\lambda, 0 \leqq \lambda \leqq 2$.

LEMMA. If $f(z)$ be an odd convex function in $E$, then $\operatorname{Re} f^{\prime}(z)>\frac{1}{2}$ for $z$ in $E$.

Proof. Let $h(z)=z+\cdots$ be regular in $E$ and $g(z)=\left(h\left(z^{2}\right)\right)^{\frac{1}{2}}$. Then $g(z)$ is an odd starlike function in $E$ if and only if $h(z)$ is starlike in $E$. For a starlike function $h(z)$, we have $\operatorname{Re}(h(z) / z)^{\frac{1}{2}}>\frac{1}{2}$ [6] for all $z$ in $E$. Therefore $\operatorname{Re}(g(z) / z)$ $=\operatorname{Re}\left(h\left(z^{2}\right) / z^{2}\right)^{\frac{1}{2}}>\frac{1}{2}$ for $z$ in $E$. Now the lemma follows on noting that $f(z)$ is an odd convex function in $E$ if and only if $z f^{\prime}(z)$ is an odd starlike function in $E$.

The corollary 2 follows from the above lemma and Theorem 2 . The last statement in the corollary follows from a result of Noshiro [3] on noting that $\operatorname{Re} F^{\prime}(z)>0$ for $z$ in $E$ for all $\lambda, 0 \leqq \lambda \leqq 2$.

Corollary 3. If $f(z)$ be starlike in E, then 


$$
F(z)=(1-\lambda) z+\lambda \int_{0}^{z}(f(z) / z)^{\alpha} d z
$$

is starlike for all $\lambda, 0 \leqq \lambda \leqq 1$, and for all $\alpha, 0 \leqq \alpha \leqq \frac{1}{2}$.

Proof. Let $g(z)=\int_{0}^{z}(f(z) / z)^{x} d z$. Then it is easy to see that $g(z)$ is convex in $E$. Also $f(z)$ being starlike, we have $\operatorname{Re}(f(z) / z)^{\frac{1}{2}}>\frac{1}{2}$, from which it follows that $|\arg (f(z) / z)| \leqq \pi \alpha \leqq \pi / 2$ for $0 \leqq \alpha \leqq \frac{1}{2}$. Thus we see that $\operatorname{Re} g^{\prime}(z)>0$ for $z$ in $E$. Now the corollary follows from Theorem 2 .

Let $S$ denote the class of starlike functions $f(z)$ which are regular and starlike in $E$ and satisfy the condition $\left|\left(z f^{\prime}(z) / f(z)\right)-1\right|<1$ for $z$ in $E$. This class has been studied by one of the authors [4].

THEOREM 3. If $f(z)$ belongs to $S$, then

$$
F(z)=(1-\lambda) z+\lambda f(z)
$$

belongs to $\bar{S}$ for all $\lambda, 0 \leqq \lambda \leqq 1$.

Proof. The function $f(z)$ belongs to $\bar{S}$ if and only if $f(z)$ has the representation

$$
\log (f(z) / z)=\int_{0}^{z} \phi(t) d t,
$$

where $\phi(z)$ is regular and $|\phi(z)| \leqq 1$ for $z$ in $E$ [4]. From (10), we have

$$
\begin{aligned}
|\arg (f(z) / z)| & =|\operatorname{Im} \log (f(z) / z)| \\
& \leqq\left|\int_{0}^{z} \phi(t) d t\right| \\
& \leqq r
\end{aligned}
$$

whence $\operatorname{Re}(f(z) / z)>0$ for $z$ in A.

Now from (9), we have

$$
\left|\frac{z F^{\prime}(z)}{F(z)}-1\right| \leqq \frac{\left|\frac{z f^{\prime}(z)}{f(z)}-1\right|}{\left|\frac{\mu z}{f(z)}+\right|}<1,
$$

Since $\left|\left(z f^{\prime}(z) / f(z)\right)-1\right|<1$ and $\operatorname{Re}(f(z) / z)>0$ for $z$ in $E$.

\section{References}

[1] S. D. Bernardi, 'Convex and starlike univalent functions', Trans. Amer. Math. Soc.135 (1969), $429-446$.

[2] R. J. Libera, 'Some classes of regular univalent functions', Proc. Amer. Math. Soc. 16 (1965), 755-758. 
[3] K. Noshiro, 'On the univalency of certain analytic functions', J. Fac. Sci. Hokkaido. Imp. Univ. 2 (1934), 89-101.

[4] Ram Singh, 'On a class of starlike functions', Compositio Mathematica 19 (1967), 78-82.

[5] K. Sakaguchi, 'On a certain univalent mapping', J. Math. Soc. Japan. 11 (1959), 72-86.

[6] E. Strohhacker, 'Beitrage zur Theorie derschlichten Funktionen', Math. Z. 37 (1933), 356-380.

[7] S. Y. Trimble, 'The convex sum of convex functions', Math. Z. 109 (1969), 112-114.

Punjabi University

Patiala, (India) 